\title{
Undergraduate and Postgraduate Education During Lockdown Due to COVID-19 Pandemic in Bangladesh
}

\author{
Seefat E Mannan ${ }^{1}$, Md. Iftakhar Parvej ${ }^{2}{ }^{*}$, Mimma Tabassum ${ }^{3}$, Firoz Ahmed ${ }^{\mathbf{4}}$ \\ ${ }^{1}$ Department of Social Work, Noakhali Science and Technology University, Noakhali, Ban gladesh \\ ${ }^{2,3}$ Department of Statistics, Noakhali Science and Technology University, Noakhali, Bangladesh \\ ${ }^{4}$ Department of Microbiology, Noakhali Science and Technology University, Noakhali, Bangladesh \\ seefatemannanm@gmail.com,iftakhar.nstu@gmail.com,tabassum021521@gmail.com, \\ firoz19701016@gmail.com
}

\begin{abstract}
In Bangladesh like the other nations around the world, the educational sector is highly affected due to COVID-19 lockdown. To know the overall picture of higher education during this lockdown and the perception of online education this study is conducted on 948 students. Our study findings show that around $73.7 \%$ of the students were involved in online education. $85.1 \%$ of the students used android mobile phones for attending online education and most (70.7\%) of the respondents faced poor internet connection. The study also finds the percentage distribution in terms of the respondent's institution. Almost half of the students of private universities are from urban areas and they spend more time per week in online education compared to college and public university students. It is a big challenge for some of the students for attaining online platforms.
\end{abstract}

Keywords

COVID-19; pandemic, online education; University and College students; Bangladesh

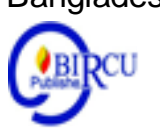

\section{Introduction}

Wuhan, China was identified as the first emerging place of corona virus disease (COVID-19) in late December of 2019 (Lai et al., 2020). Almost every nation throughout the world has been facing the severe consequences of this outbreak. On March 11, 2020, the World Health Organization declared it as a pandemic due to its widespread impact towards mankind (WHO, 2020). Most of the nations of the world have been practicing social distancing, avoiding face-to-face learning to minimize the transmission of the disease (Gonzalez et al., 2020). 'Never before have we witnessed educational disruption on such a large scale" said UNESCO Director General. The global academic calendar has been thrown into a state of disarray by the COVID outbreak. Most schools from basic to universities have shut down their doors and students have returned home to their parents and together self-quarantined (UNESCO Institute, 2020). UNESCO has indicated that around 40 million learners are affected in Bangladesh due to COVID-19 and about 1.2 million are in the tertiary level of education (UNESCO, 2020b).

On 8 March, Bangladesh confirmed its first COVID-19 case (REUTERS, 2020). Inevitably, from 18 March all educational institutions were closed and students' residence halls were vacant immediately to maintain the social distance (Dhaka Tribune, 2020). On 22 March, Bangladesh announced a 10 days shutdown on 22 March which was effective after four days of announcement to control the spread of the COVID-19 (Tribune, 2020). As of September 08, 2020,the death toll crossed 8,90,260 while the total number of infections is beyond 27 million, across the world (Medicine, 2020). With the onset of 
COVID-19 Pandemic, the global education system is going through an unprecedented disruption.

Covid-19 outbreak has had devastating impacts on various sectors. Education is no exception. Due to travel restrictions, social distancing, isolation, quarantines, campus closures, and border closures students across the higher education sector have been severely impacted by the spread of this pandemic. Similarly, these sudden closures created a huge mess in the socio-economic sector. Regarding the situation, UNESCO suggested to switch to a distance learning process and open platforms for both the teachers and learners (UNESCO, 2020a). In Bangladesh, some private universities have started and also maintain online classes now. On the other hand public institutions are still lagging far behind (Standard, 2020). In this time of crisis, Bangladesh is badly in need of a wellstructured and fruitful educational practice for the capacity-building of young generations. It will help them to minimize the educational gap and upgrade their skills, creativity and ensure the overall advancement of the education sector in Bangladesh.

To know the overall scenario of higher education, perception of students about online education and problems related to study due to the COVID-19 lockdown in Bangladesh are the main purpose of this study. We think our findings will help the government, policymakers, and institutional authorities to plan an academic future for universities and colleges students to continue the online education process and overcome this educational gap effectively.

\section{Research Method}

A self-administrated questionnaire was used to collect the quantitative information from the participants. Undergraduate and postgraduate students studying in various colleges, private and public universities in Bangladesh were the participants of this study. An online survey was conducted from 30 July to 31 August 2020 to collect the information. The questionnaire contained some demographic characteristics and information about online classes, their experience and challenges. Questionnaire links using 'Google form' were sent to respondents through email and Facebook messenger. Prior to starting the survey, the aims, objectives and the confidentiality of given responses were clarified with participants. At first the participants gave their consent to participate by clicking either "Yes" or "No." A total of 948 students provided complete information regarding the survey.

Descriptive statistics were used to find out the overall situation of study participants. Only frequency and percentages were estimated to know the overall condition of educational status and problems related to study due to the lockdown. The statistical analysis was conducted by IBM SPSS Statistics 25.0.

\section{Discussion}

\subsection{Demographic Characteristics of the Participants}

A total of 948 questionnaires out of 1083 were returned. We had the responding rate of $87.5 \%$, which has been an acceptable rate. The demographic information of the participants is displayed in Table 1. Of 948 students, $62 \%$ of them were aged below 22 years, where the median age of the respondents were 21 years. $41.5 \%$ of the participants were female. Current place of residence of the respondents are $36 \%$ from rural, $25.1 \%$ 
from semi-urban and $38.9 \%$ from urban areas. The majority of them were from public universities $(56.1 \%)$. Around $51.5 \%$ of the students were from the science background.

Table 1. Demographic Characteristics of the Participants (n-948)

\begin{tabular}{lll}
\hline Characteristics & Frequency & Percentages (\%) \\
\hline Age & 588 & 62.0 \\
Below 22 & 360 & 38.0 \\
22 and above & & \\
Gender & 393 & 41.5 \\
Female & 555 & 58.5 \\
Male & & \\
Current place of residence & 341 & 36.0 \\
Rural & 238 & 25.1 \\
Semi-Urban & 369 & 38.9 \\
Urban & & \\
Institutions & 106 & 11.2 \\
Colleges & 310 & 32.7 \\
Private University & 532 & 56.1 \\
Public University & & \\
Academic background & 488 & 51.5 \\
Science & 350 & 36.9 \\
Arts & 110 & 11.6 \\
Commerce &
\end{tabular}

\subsection{Educational Status of the Respondents}

Several questions were asked to the participants about their educational status. Some of them are presented in Table 2. More than half of the participants have no study materials (books, laptops). 53.4\% of the participants did not prefer online classes. Almost one-fourth of the respondents did not attain their online classes.

Table 2. Educational Status During Lockdown (n-948)

\begin{tabular}{lcc}
\hline Variables & Frequency & Percentages (\%) \\
\hline Having Study materials & 454 & 47.9 \\
Yes & 494 & 52.1 \\
No & & \\
Preference of online classes & 506 & 53.4 \\
Yes & 442 & 46.6 \\
No & & \\
Participating online classes & 699 & 73.7 \\
Yes & 249 & 26.3 \\
No & & \\
\hline
\end{tabular}




\subsection{Respondents Perception about Online Classes}

Respondents who attained the online classes, among of them $60.3 \%$ were attending online classes less than 5 hours per week. Maximum of this study respondents $(85.1 \%)$ used smartphones for attending online class and another $14.9 \%$ of students used their laptops, personal computer and tab for online education purposes. $63.7 \%$ of the respondents used mobile data to attain their online education. Only $14.9 \%$ of the students give their full attention during the online classes and $47.1 \%$ attain the online examination. Three of every ten participants think that it is not essential to continue the online learning during lockdown. For online class, students were using various platforms such as the Google classroom, Zoom app, Skype. Facebook messenger, Team link, Google meets/hangout etc. Our study found that $40.8 \%$ of the respondents used the Zoom app for attending online classes or e-lectures. Google classroom $(28.3 \%)$ and Google meets/hangout (16.3\%) were also popular platforms for online lectures (Table 3).

Table 3. Perception about Online Classes (n-699)

\begin{tabular}{|c|c|c|}
\hline Variables & Frequency & Percentages $(\%)$ \\
\hline \multicolumn{3}{|c|}{ Hours giving online classes per week } \\
\hline 01-02 hours & 215 & 30.8 \\
\hline 03-04 hours & 206 & 29.5 \\
\hline 05-06 hours & 113 & 16.2 \\
\hline Above 06 hours & 165 & 23.6 \\
\hline \multicolumn{3}{|c|}{ Gadgets for participate online classes } \\
\hline Laptop or Computers & 94 & 13.5 \\
\hline $\mathrm{Tab}$ & 10 & 1.4 \\
\hline Smartphone & 595 & 85.1 \\
\hline \multicolumn{3}{|c|}{ Internet connection for online classes } \\
\hline BroadBand & 254 & 36.3 \\
\hline Mobile Data & 445 & 63.7 \\
\hline \multicolumn{3}{|c|}{ Concentration during online classes } \\
\hline Yes & 104 & 14.9 \\
\hline Average & 378 & 54.1 \\
\hline No & 217 & 31.0 \\
\hline \multicolumn{3}{|c|}{ Participate online examination } \\
\hline Yes & 329 & 47.1 \\
\hline No & 370 & 52.9 \\
\hline \multicolumn{3}{|c|}{ Essential to continue this online learning during lockdown } \\
\hline Yes & 286 & 40.9 \\
\hline No & 199 & 28.5 \\
\hline Not decided & 214 & 30.6 \\
\hline \multicolumn{3}{|c|}{ Platforms for online classes } \\
\hline Google classroom & 198 & 28.3 \\
\hline Zoom App & 285 & 40.8 \\
\hline Facebook messenger & 65 & 9.3 \\
\hline Google meet & 114 & 16.3 \\
\hline Others & 37 & 5.3 \\
\hline
\end{tabular}




\subsection{Problem Facing During Online Classes}

Among the study participants 699 of them attain the online learnings and most of them $(78.4 \%)$ are facing different kinds of problems. Among them $70.7 \%$ of the respondents have poor internet connection and $14.5 \%$ having lack of logistic support. Only $17.6 \%$ are living under the proper internet support territory. And $29.9 \%$ of the respondents receive digital support from institutions (Table 4).

Table 4. Problem Facing During Online Classes (n-699)

\begin{tabular}{lll}
\hline Variables & Frequency & Percentages (\%) \\
\hline Problem facing during online classes & 548 & 78.4 \\
Yes & 151 & 21.6 \\
No & & \\
Kind of Problems & 99 & 14.5 \\
Lack of logistic support & 468 & 70.7 \\
Poor internet connection & 98 & 14.8 \\
Others & & \\
Proper internet support in the living territory & 123 & 17.6 \\
Yes & 158 & 22.6 \\
No & 418 & 59.8 \\
Average & & \\
Provide digital support by institution & 205 & 29.3 \\
Yes & 494 & 70.7 \\
No & & \\
\hline
\end{tabular}

\subsection{Time Spend and Problem Faced in Study Due to COVID-19 Lockdown}

Our study found that most $(59.4 \%)$ of the students spent their day by using social media. Most of the students were not familiar with the kind of e-learning procedure. Almost $78.1 \%$ of the students think that online classes are not similarly helpful like face to face classes. Most $(69.25 \%)$ of them prefer native language to communicate during classes. Half of the respondents did not want online education as a part of the educational system after lockdown reopens.

\subsection{Participants Characteristics and Perception about Online Classes in Terms of Institution \\ The study wants to find the scenario in terms of institutional category. Table 5 displays the characteristics of them. Almost half (48.1\%) of the college students are from rural areas in our study but a diverse scenario for private universities that is half (49.4\%) of them from urban areas. Other characteristics are almost the same for all three categories. Maximum of these study participants were from the Science background $(71.9 \%)$ in private universities.}

Table 5. Demographic Characteristics of the Participants in Terms of Institution (n-948)

\begin{tabular}{lllll}
\hline \multicolumn{5}{c}{ Number (\%) } \\
\hline \multicolumn{5}{c}{ Institutional categories } \\
\hline Characteristics & Total & Colleges & Private University & Public University \\
\hline & $948(100)$ & $106(11.2)$ & $310(32.7)$ & $532(56.1)$
\end{tabular}




\begin{tabular}{lcccc} 
Sex & & & & \\
Female & $555(58.5)$ & $57(53.8)$ & $101(32.6)$ & $235(44.2)$ \\
Male & $393(41.5)$ & $49(46.2)$ & $209(67.4)$ & $297(55.8)$ \\
$\begin{array}{l}\text { Current place of living } \\
\text { Rural }\end{array}$ & & & \\
Semi-Urban & $341(36.0)$ & $51(48.1)$ & $84(27.1)$ & $206(38.7)$ \\
Urban & $238(25.1)$ & $28(26.4)$ & $73(22.5)$ & $137(25.8)$ \\
Academic background & $369(38.9)$ & $27(25.5)$ & $153(49.4)$ & $189(35.5)$ \\
Science & $488(51.5)$ & $38(35.8)$ & $223(71.9)$ & $227(42.7)$ \\
Arts & $350(36.9)$ & $41(38.7)$ & $48(15.5)$ & $261(49.1)$ \\
Commerce & $110(11.6)$ & $27(25.5)$ & $39(12.6)$ & $44(8.3)$ \\
Study Materials & & & & \\
Yes & $454(47.9)$ & $71(67.0)$ & $182(58.7)$ & $331(62.2)$ \\
No & $494(52.1)$ & $35(33.0)$ & $128(41.3)$ & $201(37.8)$ \\
Prefer Online Classes & & & & \\
Yes & $506(53.4)$ & $83(78.3)$ & $130(41.9)$ & $293(55.1)$ \\
No & $442(46.6)$ & $23(21.7)$ & $180(58.1)$ & $239(44.9)$ \\
Participating in online classes & & & \\
Yes & $699(73.7)$ & $78(73.6)$ & $244(78.7)$ & $377(70.9)$ \\
No & $249(26.3)$ & $28(26.4)$ & $66(21.3)$ & $155(29.1)$ \\
\hline
\end{tabular}

Table 6 shows the perception about online classes and the study revealed that private university students gave more time per week in online classes compared to college and public university students. Around $45.1 \%$ of the students spend more than 06 hours per week in private universities. Other variables are not very much dependent on the institutions.

Table 6. Perception about Online Classes in Terms of Institution (n-699)

\begin{tabular}{|c|c|c|c|c|}
\hline \multicolumn{5}{|c|}{ Number (\%) } \\
\hline & & Institutio & al categories & \\
\hline \multirow[t]{2}{*}{ Variables } & Total & Colleges & Private University & Public University \\
\hline & $699(100)$ & $78(11.2)$ & $244(34.9)$ & $377(53.9)$ \\
\hline \multicolumn{5}{|c|}{ Hours giving online classes per week } \\
\hline 01-02 hours & $215(30.8)$ & $31(38.7)$ & $41(16.8)$ & $143(37.9)$ \\
\hline 03-04 hours & $206(29.5)$ & $29(37.2)$ & $52(21.3)$ & $125(33.2)$ \\
\hline 05-06 hours & $113(16.2)$ & $7(9.0)$ & $41(16.8)$ & $65(17.2)$ \\
\hline Above 06 hours & $165(23.6)$ & $11(14.1)$ & $110(45.1)$ & $44(11.7)$ \\
\hline \multicolumn{5}{|c|}{ Internet connection for online classes } \\
\hline BroadBand & $254(36.3)$ & $34(43.6)$ & $104(42.6)$ & $116(30.8)$ \\
\hline Mobile Data & $445(63.7)$ & $44(56.4)$ & $140(57.4)$ & $261(69.2)$ \\
\hline \multicolumn{5}{|c|}{ Gadgets for participate online classes } \\
\hline Laptop or Computers & $94(13.4)$ & $8(10.3)$ & $42(17.2)$ & $44(11.7)$ \\
\hline Tab & $10(1.4)$ & $1(1.3)$ & $5(2.0)$ & $4(1.1)$ \\
\hline Smartphone & $595(85.1)$ & $69(88.5)$ & $197(80.7)$ & $329(87.3)$ \\
\hline \multicolumn{5}{|c|}{ Problem facing during online classes } \\
\hline Yes & $548(78.4)$ & $56(71.8)$ & $192(78.7)$ & $300(79.6)$ \\
\hline
\end{tabular}


Proper internet support in the living territory

$\begin{array}{lllll}\text { Yes } & 123(17.6) & 28(35.9) & 40(16.4) & 55(14.6) \\ \text { No } & 158(22.6) & 5(6.4) & 61(25.0) & 92(24.4) \\ \text { Average } & 418(59.8) & 45(57.7) & 143(58.6) & 230(61.0)\end{array}$

Provide digital support by institution

Yes

Our study revealed that it is a big challenge for some of the students to attain the online platforms. A considerable number of students could not attend online classes because students from remote areas and having vulnerable economic conditions may be a cause for denying online learning.

\section{Conclusion}

The academic activities have significantly disrupted the unexpected lockdown by COVID-19. Our study evaluated the perception of the online education of students studying in various colleges, private and public universities in Bangladesh during this pandemic. Many of the students face some challenges to continue the online study. Our study has revealed the overall scenario and the perceptions about online classes in college and university level. We think that this study will be helpful for the government, policymakers, and institutional authorities to make an academic decision. By using this information, they can make a plan for the higher educational institution to continue the online education process during this COVID-19 lockdown.

\section{Acknowledgements}

We gratefully acknowledge all the participants for their contribution to this study. We are also grateful to all interviewers for their contribution in data collection.

\section{References}

Dhaka Tribune. (2020). Bangladesh closes all educational institutions till March 31.

Gonzalez, T., De La Rubia, M. A., Hincz, K. P., Comas-Lopez, M., Subirats, L., Fort, S., Sacha, G. M., \& Spain, M. (2020). Influence of COVID-19 confinement in students' performance in higher education. In arxiv.org. https//arxiv.org/abs/2004.09545

Lai, J., Ma, S., Wang, Y., Cai, Z., Hu, J., Wei, N., Wu, J., Du, H., Chen, T., \& Li, R. (2020). Factors associated with mental health outcomes among health care workers exposed to coronavirus disease 2019. JAMA Network Open, 3(3), e203976-e203976.

Medicine, J. H. U. \&. (2020). CORONAVIRUS RESOURCE CENTER. https://coronavirus.jhu.edu/map.html

REUTERS. (2020). Bangladesh confirms its first three cases of coronavirus. https://www.reuters.com/article/us-health-coronavirus-bangladesh-idUSKBN20V0FS

Standard, T. B. (2020). Online classes for university students in Bangladesh during the Covid-19 pandemic- is it feasible? https:/tbsnews.net/thoughts/online-classesuniversity-students-bangladesh-d uring-covid-19-pandemic-it- feasib le- 87454

Tribune, D. (2020). Coronavirus: Bangladesh declares public holiday from March 26 to 
April 4. https $/ / w w w . d h a k a t r i b u n e . c o m / b a n g l a d e s h / 2020 / 03 / 23 / g o v t-o f f i c e s-t o-$ remain-closed-till-april-4

UNESCO. (2020a). 290 million students out of school due to COVID-19: UNESCO releases first global numbers and mobilizes response. https://en.unesco.org/news/290million-students-out-school-due-covid-19-unesco-releases-first-global-numbers-andmobilizes

UNESCO. (2020b). Education: From disruption to recovery (COVID-19 Impact on Education). https://en. unesco.org/covid19/educationresponse/

UNESCO Institute. (2020). UNESCO rallies international organizations, civil society and private sector partners in a broad Coalition to ensure \#LearningNeverStops.

WHO. (2020). WHO Director-General's opening remarks at the media briefing on

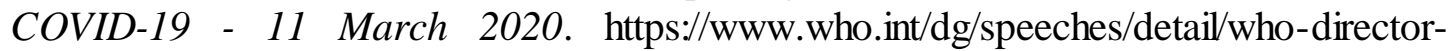
general-s-opening-remarks-at-the-media-briefing-on-covid-19---11-march-2020. 